\title{
Sustainability and accessibility: the Design for All approach
}

\author{
Isabella Steffan ${ }^{\mathrm{a}, *}$ \\ ${ }^{\mathrm{a}}$ Studio Steffan - Progettazione \& Ricerca - Via G.C. Procaccini, 69 - 20154 Milano
}

\begin{abstract}
A sustainable project should also be affordable, and it is cheaper if it its affordability is guaranteed to as much people as possible since the first phases of the project without any modifications. The author illustrates the activity of diffusion of DfA on an urban scale carried out on didactic and cultural level.
\end{abstract}

Keywords: sustainability, accessibility, Design for All, teaching DfA, disseminating DfA

\section{Introduction and objectives}

In the present atmosphere of emergency, society is directing strongly its efforts to energy conservation, an unavoidable objective for designers.

The concept of sustainability goes beyond energy conservation, and leads towards a sort of "widened sustainability": environmental, economic, social, institutional.

The unsustainability of the current way of living and consuming non-renewable resources of the planet, is leading society inevitably to think about its life and, as a consequence, about its way of thinking, designing and making architecture.

A sustainable project - involving product and architectural, urban or territorial issues - has to be also affordable, and it is more affordable if its affordability is guaranteed since the first phases of the project without bringing any change $a$ posteriori, when they are more expensive and less sustainable. By this point of view Design for All - the project for the social inclusion that addresses to and gives value to human diversity - is a way to design for the achievement of the environmental, economical and social sustainability.
Sustainable environmental design is a design approach that goes beyond the concept of first generation sustainable consumption (report Brundtland 1987); it is design consistent with human and social Development and meeting responsible needs, as Social Human Rights of the current generation - without depriving future generations of vital resources.

Sustainable design means operating in a place and highlighting environmental qualities as well as social and cultural values. Its objective is contributing to health, comfort and safety of inhabitants, today and in the future.

Such development respects biologic, social and cultural diversity of people but also the character of the place, "genius loci", and considers at the same time the local community needs.

\section{Method}

All the solutions proposed by environment design should be for All, consistent with the needs of most people and realized by the use of materials consistent with the environment, so their impact will be the most sustainable possible.

\footnotetext{
"Corresponding author. E-mail: info@studiosteffan.it.
} 
With the aim to develop these themes on a cultural level, in 2004 the author has started a multidisciplinary team, the CQA Commissione per la Qualità dell'Ambiente (Commission for the Quality of the Environment), in the ambit of the College of Engineers and Architects of Milan, organizing different meetings and conferences. Two of them, organized in 2008-2009, represented the occasion for a debate before the announcement of a competition for the redecoration of the ex-barracks San Paolo in Monza (Figure. 1), to be converted in a municipal library ${ }^{1}$.

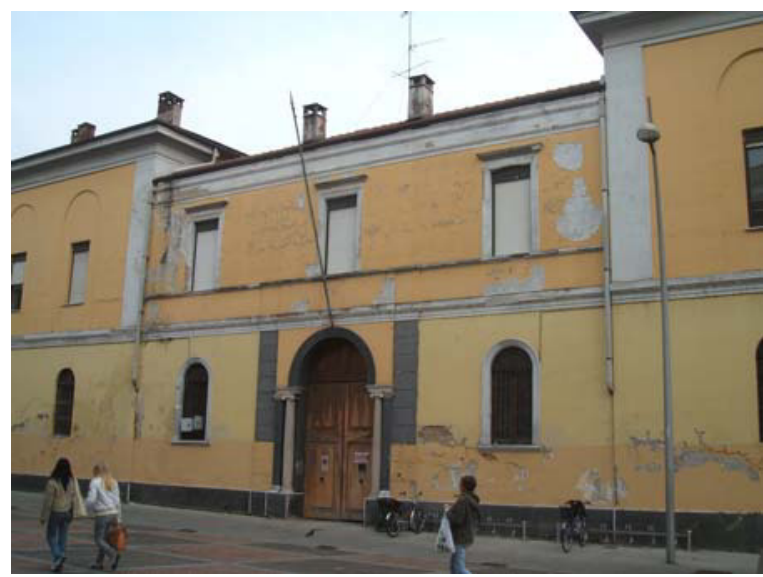

Fig. 1 - Ex-barracks entrance.

On a didactic level, in the last two academic years, in the Laboratory of urban and architectural design (Architect Professor Alberico B. di Belgiojoso) it was held an integrative course "Economic Sustainability of building: Design for All approach", attended by students of the last degree course in architecture. In the Master Course promoted by SIE Marche ${ }^{2}$ a session on Design for All has been held.

In the DfA teaching method the author has introduced, beside academic lessons, an experiential session involving the emotional experience (the exhibition "Dialogo al buio" in Milan, the visit at the centre "Lega del Filo d'Oro" in Ancona), and the pragmatic experience (simulation of motor and sensory disabili-

\footnotetext{
1 The International announcement of competition of design "Requalification and rebuilding of spaces in the ex-barracks Piazza San Paolo to be converted in the new General Central Library of information and culture of the town of Monza was issued on 7 July 2011 .

2 The Master Course SIE- Società Italiana di Ergonomia (Italian Society of Ergonomics) "Ergonomia e prevenzione. Criteri e metodi sostenibili per il benessere occupazionale" ("Ergonomics and prevention. Sustainable criteria and methods for occupational comfort") was held in Ancona during summer-autumn 2011.
}

ty in urban context), with collective discussion of the analysis carried out, criticalities found and possible solutions, in collaboration with associations and local institutions, as demanded by the DfA approach.

Twelve groups of students of architecture have worked on different areas of Milan, have analyzed problems and potentialities of each area and have elaborated project proposals to improve the quality and liveableness of the city, also in terms of sustainability and Design for All on an urban scale, considering the real needs and aspirations of inhabitants.

The analysis has been carried out, in some cases, in collaboration with some associations making use of studies on pedestrian flux, interviews and reviews.

The Design for All approach has allowed to:

- design spaces for all rather than reserved spaces;

- research solutions for environments that allow autonomy and safety for all;

- achieve solutions for non-energy-consuming, slow and protected mobility as pedestrian spaces and cycle lanes;

- research sustainable solutions that prevent situations of disease, for example avoiding the use of allergenic plants;

- research solutions that prevent risky situations and avoid daily accidents.

The discussion has lingered longer on safety problems because the problem of road safety in Milan is extremely serious: the number of accidents and injuries is growing. The situation appears even more dramatic if one considers the decrease of population in Milan, in particular school population.

With reference to the period 1995-1999, almost 1.000 young people under 14 , injured or killed as pedestrians or bikers3. This data is impressive and imposes a consideration on both project and political level, for a higher social, environmental and economic sustainability.

\section{Results and discussion}

In particular, the research has focused on the readability of the territory and the possibility to circulate in complete safety, also for people with motor, sensory or cognitive disabilities, old people, children and foreigners.

\footnotetext{
${ }^{3}$ From the study "Safer traffic for our schools" (CST and Studio Steffan for the Municipality of Milan, 2003).
} 
Some groups have analyzed the issue of configuration of spaces to enhance orientation actions.

A group has pointed out that Landmarks (two roman towers in the area of the ancient amphitheatre in Brisa street), important for the local historical and social identity, are not recognizable anymore, because of modern buildings. This architectural problem has been compensated with a half pedestrian urban museum path, which resulted to be particularly communicative.

Some groups have worked on the organization of spaces, analyzing in particular safety in those zones where cycle lanes and pedestrian crossing or pedestrian crossings and car lanes meet.

The effort has been guaranteeing more environmental communication on the walkable surface by means of materials differentiation, size, laying, manufacturing and colour.

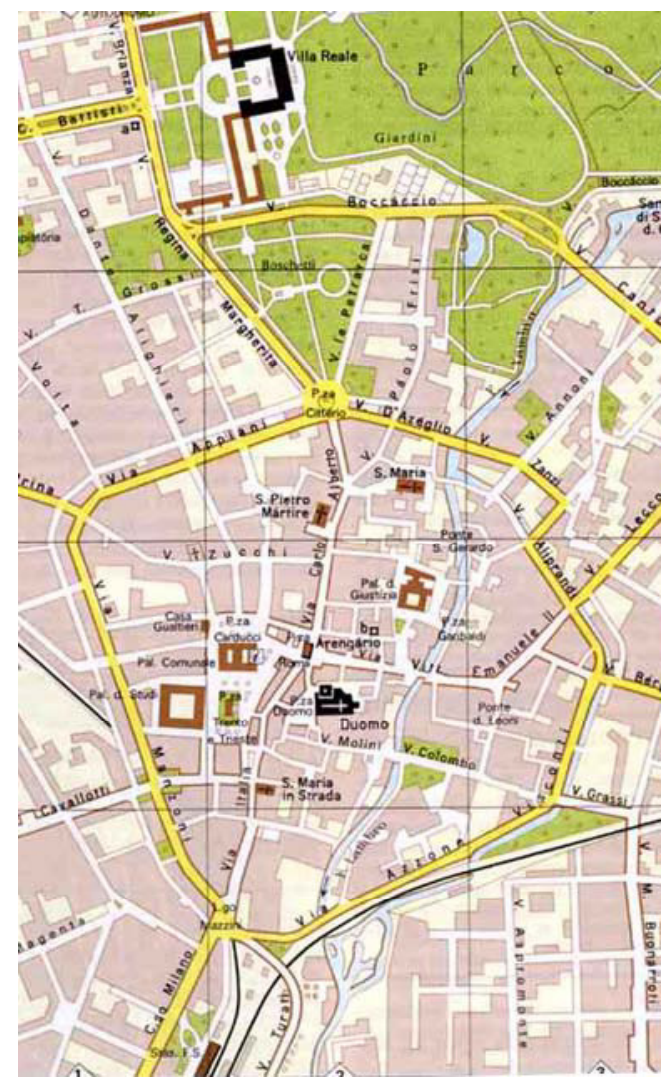

Fig. 2 - Monza touristic map.

As regards the congresses in Monza, organized in close collaboration with political representatives of the Town of Monza, it has been suggested the development of a safe network between the train station and the historical centre, till the ex-barracks. (Figure. 2 - Figure. 3)

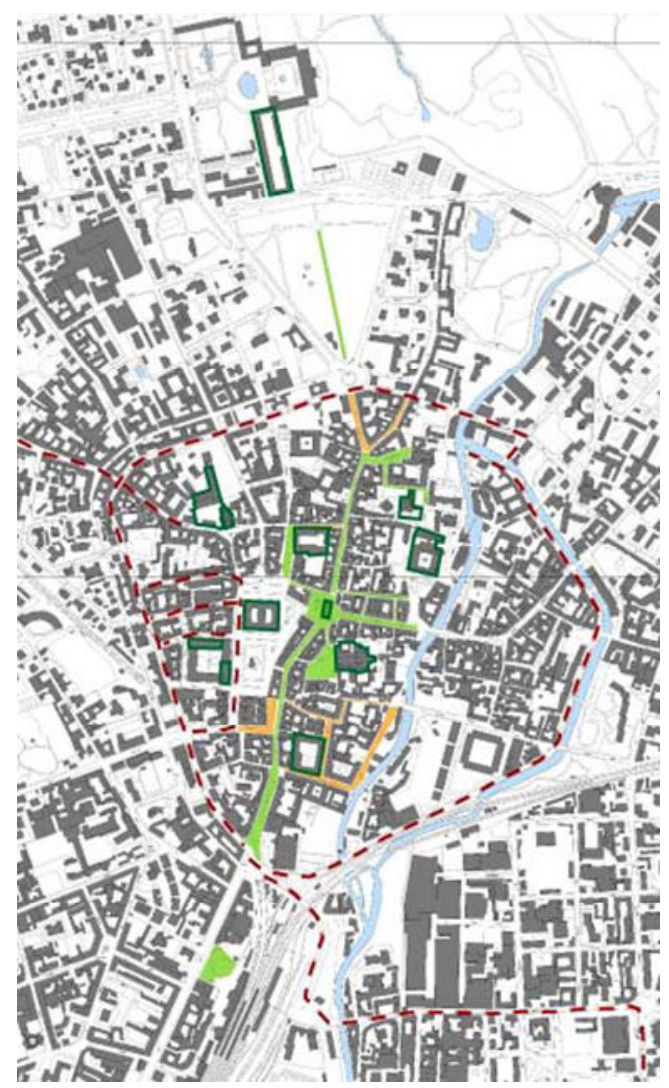

Fig. 3 - Monza urban map.

This way owns different characteristics to be part of a future network for All: it is sufficient to solve some critical points noticed - especially in the areas of connection - and implement more easily and safely the pedestrian, bicycle and public transport link without energy consumption, with Villa Reale (main point of local historical interest).

The above mentioned complex issues should always be faced on a global level by Public Administrations with an approach of inclusive planning, involving citizens in the first phases of the process and also in the phases of the final check.

In fact, DfA needs the involvement of real users and real decision makers, since the first phases of the project. 


\section{References}

[1] Arthur, P. \& Passini, R., Wayfinding. People, Signs and Architecture, McGraw-Hill, New York, 1992.

[2] Laurìa, A. Pedonalità urbana. Percezione extra-visiva, orientamento, mobilità. Maggioli, Santarcangelo in Romagna, 1994.

[3] Lynch, K., The Image of the City, MIT Press, Cambridge, MA, 1960.
[4] Steffan I., "Design, Ergonomia e Sostenibilità:conclusioni di un convegno a Ecocentrica", in Rinaldi A., Steffan I., Tosi F., "Ergonomia, Design For All e Sostenibilità", Ambrosiana Arti grafiche srl, La Spezia, 2011, ISNB 978-88-90256-6-2.

[5] United Nations, Convention on the Right of Persons with Disabilities, 2006.

[6] World Commission on Environment and Development, Our Common Future (The Brundtland Report), Oxford, Oxford University Press, 1987. 